\title{
Stem cell quest
}

\author{
Alexandra Irvine
}

Received: 28 January 2015 / Accepted: 28 January 2015 / Published online: 20 February 2015

(C) The International CCN Society 2015

\begin{abstract}
Chronic Myeloid Leukaemia has been a valuable model system for experimental haematologists for many years. Virtually all patients ( $>95 \%)$ have the same genetic change which has driven the development of the first targeted therapies, tyrosine kinase inhibitors (TKIs). Since the introduction of TKIs in 2000 it has become clear that this approach has significantly improved the outcome for these patients. Nevertheless drug resistance inevitably develops and it is clear that the disease is controlled rather than eradicated. The recent publication by Herrmann et al. has defined a sub-population of leukaemic stem cells which are responsible for propagating the disease. CD26 now provides a new specific target for the malignant stem cells and offers the possibility of true curative therapy.
\end{abstract}

Keywords Chronic Myeloid Leukaemia · Stem cells · CD26

Chronic Myeloid Leukaemia (CML) is characterised by the presence of the Bcr-Abl fusion gene in greater than $95 \%$ of patients. This fusion gene codes for an activated tyrosine kinase which has provided the rationale for design of a class of drugs called tyrosine kinase inhibitors (TKIs). These TKIs have proven very successful in the clinic but drug resistance develops and second and third generation compounds ultimately result in similar resistance problems. It is now generally accepted that TKIs do not eradicate the disease. The hypothesis is that only a subset of leukaemic cells display long term self-renewal and are responsible for propagating leukaemia; these LSC escape.

Targeting leukaemic stem cells (LSC) is complex, an important aspect of which is that they interact with the bone marrow environment or stem cell niche. Currently it is accepted that LSC reside in the CD34+ CD38- Lin- fraction but this also contains normal stem cells. Peter Valents' group have found that CD26 is a specific biomarker of CML LSCs in the CD34+ CD38- Lin- fraction (Herrmann et al. 2014). CD26, Dipeptidylpeptidase IV, is a surface enzyme which degrades SDF-1 and thereby promotes the niche escape of LSC hence potentially contributing to extramedullary myeloproliferation in CML. This paper is exciting in the field of CML and stem cell research in that identifies a specific new biomarker of CML LSCs and provides a potential target for curative therapy for this disease.

\section{References}

Herrmann H, Sadovnik I, Cerny-Reiterer S, Rülicke T, Stefanzl G, Willmann M, Hoermann G, Bilban M, Blatt K, Herndlhofer S, Mayerhofer M, Streubel B, Sperr WR, Holyoake TL, Mannhalter C, Valent P (2014) Dipeptidylpeptidase IV (CD26) defines leukemic stem cells (LSC) in chronic myeloid leukemia. Blood 123(25): 3951-62

\footnotetext{
A. Irvine $(\triangle)$

Department of Haematology, Centre for Cancer Research and Cell

Biology, Queen's University of Belfast, Belfast, UK

e-mail: s.irvine@qub.ac.uk
} 